\title{
A Longitudinal Exploration of the Academic and Psychosocial Outcomes of Students with Emotional/Behavioural Difficulties: The Importance of Student Perceptions of Themselves, Their Peer Relationships, and Their Classrooms
}

\author{
Jessica Whitley \\ University of Ottawa \\ Edward P. Rawana \\ Lakehead University \\ Keith Brownlee \\ Lakehead Univeristy \\ Jennine Rawana \\ York University
}

\begin{abstract}
Students with emotional/behavioural difficulties (E/BD) continue to experience poor academic and psychosocial outcomes. Developing a better understanding of the ways in which indicators of these outcomes develop while students are still in early grades can assist in planning effective programming and alter negative trajectories. Accordingly, the present study sought to explore the perceptions of students with and without E/BD regarding their self-concept, classroom climate, and academic achievement over the course of one school year. The participants consisted of 68 elementary-aged students attending two schools in Northwestern Ontario. A repeated measures ANOVA was conducted and a number of significant differences were found both between groups and over time. Specifically, students in the E/BD group experienced poorer functioning compared to students without E/BD at most time points. Patterns of change in psychosocial and academic variables were largely similar across groups. Discussions of these findings, as well as implications for practice and for future research are presented.
\end{abstract}

Keywords: Emotional/behavioural difficulties; self-concept; academic achievement

Jessica Whitley is an Assistant Professor in the Faculty of Education at the University of Ottawa. Her research interests focus on documenting and improving psychosocial outcomes for students with exceptionalities and improving teacher preparation for inclusive education.

\footnotetext{
Edward Rawana is an Associate Professor in the Department of Psychology at Lakehead University. He is Director of the Lakehead Site of the Centre of Excellence for Children \& Adolescents with Special Needs (CECASN). He is a practicing psychologist with 25 years of experience working with children, adolescents and their families. His research focuses on the assessment and use of student strengths in treatment and education.
}

Keith Brownlee is the Director of Research for the Centre of Excellence for Children and Adolescents with Special Needs and a Professor in the School of Social Work at Lakehead University. His interests include clinical work with families and children, with an emphasis on personal strengths.

Jennine Rawana is an Assistant Professor in the Department of Psychology at York University. Her research interests involve studying the emergence of normative and atypical emotional development from early adolescence to emerging adulthood. Current research also includes developing and evaluating school-based prevention and mentoring programs that reduce mental health issues and build upon the strengths of children and adolescents. Brock University, Volume 19, No. 2, Spring 2010, 78-96. 


\section{A Longitudinal Exploration of the Academic and Psychosocial Outcomes of Students with Emotional/Behavioural Difficulties: The Importance of Student Perceptions of Themselves, Their Peer Relationships, and Their Classrooms}

Students who exhibit emotional and/or behavioural difficulties (E/BD) are at-risk for poor academic and psychosocial outcomes (e.g. Wood \& Cronin, 1999). Recent large-scale data from the United States (Wagner, Kutash, Duchnowski, Epstein, \& Sumi, 2005) and Canada (Whitley, Lupart, \& Beran, 2009) highlight the social and academic difficulties experienced by elementary and secondary-aged students with school-identified E/BD. In fact, according to some researchers, students with E/BD experience less school success than any other group of students, whether identified with an exceptionality or not (Landrum, Tankersley, \& Kauffman, 2003; Wagner et al., 2005; Wood \& Cronin, 1999).

Within the Canadian education system, students with E/BD may be formally identified for special education services through a combination of teacher observation and referral, parent observation, and psychological assessment (Visser, Daniels, \& Cole, 2001; Zionts, Zionts \& Simpson, 2002). This identification is dependent on a number of factors including the provincial categories or diagnoses, the severity and type of difficulties the student is identifying, the services available in the school, as well as numerous other student, teacher, and school characteristics (e.g. Lahey, Schwab-Stone, Goodman, Waldman, Canino, et al., 2000; Noble \& Bowd, 2005). Regardless of the source of the definition, however, all contain reference to students displaying behaviour problems (either internalizing or externalizing) that are severe, chronic, and pervasive, and that negatively impact the students' ability to learn and function in a classroom setting (e.g. Alberta Learning, 2009; Ontario Ministry of Education, 2001; Winzer, 2008).

It is clear from the extant literature that students displaying emotional and behavioural difficulties, whatever the exact criteria used, are at-risk for poor academic achievement and dropping out of high school, as well as psychosocial difficulties in areas such as peer relationships. Teachers consistently rate students with E/BD as having moderate to severe academic difficulties and poor social skills (Lane, Carter, Pierson, \& Glaeser, 2006; Nelson, Benner, Lane \& Smith, 2004; Soles, Bloom, Heath, \& Karagiannakis, 2008). Teachers also view students with E/BD as being more disruptive and difficult to teach, as exerting less effort and often report having more negative relationships with them compared to typically-developing peers (Birch \& Ladd, 1998; Gunter, Coutinho, \& Cade, 2002; Whitley et al., 2009). What is less clear, however, is how students with E/BD perceive themselves and their classroom environments. This is important because three facets of self-perception, namely, general and peer self-concept as well as classroom climate, have been found to be influential for outcomes among the general student body (e.g. Henderson, Dakof, Schwartz, \& Liddle, 2006; Lan \& Lanthier, 2003; Lubbers, Van Der Werf, Snijders, Creemers, \& Kuyper, 2006). Research exploring these in relation to students with $\mathrm{E} / \mathrm{BD}$ is summarized below.

\section{General Self-Concept}

Self-concept, in both peer and general areas, is an important marker of psychological adjustment for students with and without exceptionalities. Students with high self-concept have better peer and family relationships, higher grades, and lower levels of alcohol and drug use, depression, anxiety, and externalizing behaviours than those with lower self-concept (Deihl, Vicary, \& 
Dieke, 1997; DuBois, Felner, Brand, \& George, 1999; Henderson et al., 2006; Zimmerman, Copeland, Shope, \& Dielman, 1997). As well, students who have chosen to drop out of high school report declining self-concept prior to leaving school (Lan \& Lanthier, 2003).

For students with E/BD, self-concept is of particular importance given the risk these students experience for long-term difficulties (Margerison, 1996). However, few studies have explored the self-perceptions of students with E/BD with respect to their competencies and selfworth. In addition, syntheses of findings in this area are confused by the use of varying terminology and measures. Self-esteem has been defined as an individual's "positive or negative attitude toward the self as a totality" (Rosenberg, Schooler, Schoenbach, \& Rosenberg, 1995, p. 141). Indeed the Rosenberg Self-Esteem Scale (1979), one of the most widely used self-esteem measure in social science research (Whiteside-Mansell \& Corwyn, 2003), was based on a unitary conception of self-esteem and assesses self-esteem using a single score.

More recently, however, a multidimensional view of self-esteem has been endorsed and has become more prevalent in recent years. One of the most influential theories is based on a hierarchical, multidimensional model presented by Shavelson and his colleagues (Shavelson, Hubner, \& Stanton, 1976), and subsequently tested by Marsh (e.g. Marsh, 1989; Marsh \& Ayotte, 2003). According to Marsh and Shavelson (1985), self-concept is a person's perceptions of him- or her-self. It is formed through experience with interpretations of one's environment and has both a descriptive and evaluative dimension. Furthermore, self-concept consists of a general component, which is a higher order factor comprising multiple, domain-specific selfconcepts that, while related, can be viewed as separate constructs. For the present study, then, self-concept will be defined as having a general domain as well as more specific domains such as academic and peer relations self-concept. This clarification is important, as more general selfesteem measures have not always been found to be linked to academic achievement or specific behaviours, or capture differences among subgroups of students (e.g. Baumeister, Campbell, Krueger, \& Vohs, 2005; Rosenberg et al., 1995). This is due in part to the different perceptions that individuals can have of themselves simultaneously, in areas such as academics and peer relationships as well as generally. Studies that employ a unitary measure of self-esteem will be referred to as investigating self-esteem, rather than self-concept.

Early research by Lund (1986) suggested that students with emotional and behavioural difficulties who were traditionally removed from regular classrooms experienced low selfesteem. Margerison (1996), in his exploration of a cohort of elementary-aged students, found that over 12 percent of the participants had low self-esteem and that the majority of these students displayed behavioural difficulties. From his perspective, low self-esteem is one of the causal factors in $\mathrm{E} / \mathrm{BD}$ and that if the former is increased the latter will also improve. Other researchers have also documented the depressed self-esteem scores of students with E/BD relative to comparison groups (Slomkowski, Klein, \& Mannuzza, 1995; Treuting \& Hinshaw, 2001). Clearly, further research employing a multi-dimensional view of self-concept is necessary to determine whether students with E/BD do in fact report poorer general self-concept than their peers.

\section{Peer Relations Self-Concept}

As noted previously, students can have varying perceptions of their own worth and competence depending on the domain in question. Peer or social self-concept is one domain of student perception that has been found to have a positive influence on general self-concept, academic 
self-concept, and academic achievement (Marsh \& McDonald-Holmes, 1990; Lubbers et al., 2006). Peer relations self-concept refers to the ways in which individuals perceive their competence in peer relationships. As might be expected, teachers and parents consistently rate students with $\mathrm{E} / \mathrm{BD}$ as having poorer social skills and fewer friends than students without E/BD (Gresham \& MacMillan, 1997; Lane et al., 2006; Sabornie, Cullinan, Osborne \& Brock, 2005; Wagner et al., 2005).

However, contrary findings have been reported for student perceptions of their own peer relationships. A number of studies have found that students with various emotional and behavioural difficulties rate themselves as being as socially competent as their typicallydeveloping peers (Diener \& Milich, 1997; Hoza, Dobbs, Owens, Pelham \& Pillow, 2002; Hoza, Pelham, Milich, Pillow \& McBride, 1993; Whitley, Heath \& Finn, 2008). Students with E/BD also view themselves as more socially successful than their teachers (Hoza et al., 2002; Owens \& Hoza, 2003), which has been interpreted as reflective of the inability of students with E/BD to reliably assess their own skills and behaviours. Whether this finding will extend to a sample of students who self-identify as having emotional and/or behavioural difficulties will be explored in the present study.

\section{Classroom Climate}

As with self-concept, there is scarce extant literature exploring the perceptions of students with $\mathrm{E} / \mathrm{BD}$ regarding their classrooms and their relationships with their teachers. Given the research documenting the negative views of teachers regarding the behaviour of these students, as well as the academic and social difficulties that are often experienced by students with E/BD, it appears likely that these students would perceive their classroom environment less positively than their peers. Class climate, as measured by student-teacher relationship, has been found to have a significant influence on students' academic achievement, school engagement and behavioural adjustment both in the short-term and across school years (Hamre \& Pianta, 2001; Lan \& Lanthier, 2003; Mihalas, Morse, Allsopp, \& McHatton, 2009).

Mihalas and her colleagues (2009) make the argument that developing a positive classroom environment for students with E/BD and most importantly, fostering strong and supportive student-teacher relationships, is key in promoting positive outcomes. Certainly students with E/BD may not always feel welcomed in their classrooms and schools (Sutherland, Lewis-Palmer, Stichter, \& Morgan, 2008). Studies documenting less positive student-teacher relationships from the perspective of teachers support this assertion (e.g. Birch \& Ladd, 1998). Whitley et al. (2009) found that students with E/BD felt significantly more negative about school than peers without exceptionalities. However, students also reported similar perceptions to typically-achieving peers with regard to being treated fairly by their teachers and not feeling like an outsider at school. Further research is needed to explore the perceptions of students with $\mathrm{E} / \mathrm{BD}$ regarding their classrooms and teachers.

\section{Present Study}

Clearly, then, although the poor long-term outcomes of students with E/BD are widely documented, the processes by which these occur are not well understood. In particular, the perceptions of students themselves have long been overlooked as potential influences on academic achievement and psychosocial outcomes. Students with E/BD are often identified very 
early on in their school career and there are many opportunities to intervene and alter the downward trajectory that many follow (Mihalas et al., 2009; Montague, Enders, Dietz, Dixon, \& Cavendish, 2008). Developing a better understanding of the ways in which emotional and behavioural difficulties change and influence academic and psychosocial outcomes while students are still in early grades can assist in planning effective early intervention. Student general and peer self-concept as well as their perceptions of classroom climate are three variables that have been found to significantly impact student learning, engagement, and psychosocial adjustment. Thus, the present study sought to explore the perceptions of elementary-aged students regarding their self-concept, emotional/behavioural difficulties, and classroom climate over the course of one school year. The academic achievement of students were also included as a variable of interest. Specifically, our research question was as follows: Are there any differences in the self-concept, classroom climate, and academic achievement of students with emotional/behavioural difficulties and those without, both in the short- and long-term?

\section{Methods}

The data for the present analyses were drawn from a larger study focusing on bullying and violence in two elementary (K-8) schools in Northwestern Ontario. Students completed several paper-based measures related to their experiences with bullying, their behaviours, general and peer self-concept and their strengths in a number of domains. Students' grades in all subject areas were also collected. The first administration took place prior to the intervention (February, 2008: Time 1), the second in June of 2008 (Time 2) and the third in March of 2009 (Time 3). Data from all three time periods are used for the present study.

\section{Procedures}

Consent packages were sent home with all students in Grades $4-8$ that included an invitation for parents to participate in the anti-bullying project and to provide consent for their child(ren) to participate. A student assent form was also included. Those students whose parent returned a signed consent and student assent form were included in the study. Participation was limited to these grades because of the number of self-report measures that were judged to be at a reading level appropriate for students in at least Grade 4.

\section{Participants}

Of the approximately 352 potential student participants at the two schools, parental consent and student assent was obtained for 103, resulting in a return rate of 29 percent. Equal numbers of students participated at the two schools and no significant differences were found by First Nations status, gender or grade. The mean age of the student participants at the outset of the study was 10.93 years of age $(S D=1.18)$ and approximately equal numbers of male and female students took part. When asked to report their ethnicity, approximately $25 \%$ of the sample indicated that they were of First Nations descent with the remaining 75\% reporting largely European backgrounds.

For the present study, analyses were conducted on a number of student self-report measures as well as academic achievement data. Students from the larger study were retained if they had complete data on all measures at both time points, resulting in a final sample size of 65 . 
Due the longitudinal nature of our analyses, only students who were in grades 4 through 7 at Time 1 were included. Demographic characteristics for all participants at Time 1 are presented in Table 1.

Table 1

Demographic Characteristics of Participants at Time 1 by Group

\begin{tabular}{lcc}
\hline Characteristic & Comparison & E/BD \\
\hline Total & 45 & 23 \\
Gender & & \\
$\quad$ Male & 22 & 9 \\
Female & 23 & 14 \\
Grade & & \\
4 & 11 & 2 \\
5 & 9 & 5 \\
6 & 14 & 10 \\
7 & 11 & 6 \\
\hline
\end{tabular}

Once parent consent and student assent were obtained, students completed three questionnaires in small groups (5-10) at a time during the school day that was convenient for them and their teacher(s). Students completed the three questionnaires independently with assistance provided by research assistants if required. They took approximately 20 minutes to complete in total. The questionnaires consisted of a) Strengths and Difficulties Questionnaire, b) Self-Description Questionnaire and c) the Classroom Climate sub-scale.

\section{Measures}

\section{Strengths and difficulties questionnaire.}

The Strengths and Difficulties Questionnaire (SDQ) (Goodman, Meltzer, \& Bailey, 1998) is a brief behavioural screening questionnaire with parent, teacher, and self-report versions. The SDQ assesses the E/BDs of children and youth between the ages of 4 to 16 (informant-rated) and 11 to 16 (self-report) in 5 areas: conduct problems, hyperactivity, emotional symptoms, peer problems, and prosocial behaviour. Scores are calculated for each of the five areas and summing all but the prosocial behaviour score creates a total difficulties score. For each of the areas, five items are presented describing positive and negative attributes; children and youth respond to each on a 3-point scale ranging from $0=$ not true to $2=$ certainly true. The SDQ has been found to have good psychometric properties with moderate cross-informant correlations (Goodman, $1999 ; 2001)$. The self-report SDQ has been found to accurately discriminate between community and clinic-referred samples and is sensitive in detecting emotional/behavioural problems (Goodman et al., 1998; Mathai, Anderson, \& Bourne, 2002; 2004).

\section{Self-description questionnaire.}

General and Peer Self-Concept were measured using the Self-Description Questionnaire - I (SDQ-I) (Marsh, 1988). The SDQ-I is one of the most widely used and psychometrically sound measures of multidimensional self-concept (Byrne, 1996; Marsh \& MacDonald Holmes, 
1990; Marsh \& O’Neill, 1984). According to Marsh (Marsh, Craven, \& Debus, 1998), the general self-concept scale is intended to measure "student self-perceptions of themselves as effective, capable individuals who have self-confidence and self-respect and are proud and satisfied with the way they are" (p. 1051). Children and youth respond to ten items on a five point scale ranging from $1=$ false to $5=$ true. Marsh reported Cronbach's $\alpha$ for the factor as 0.81 (Marsh, 1990). In the present study, Cronbach's $\alpha$ averaged 0.84 across the three time points.

The peer self-concept scale measures "student perceptions of how easily they make friends, their popularity, and whether others want them as a friend" (Marsh et al., 1998; p. 1051). The Peer Self-Concept scale consists of nine items, which are rated by children and youth on a five point scale ranging from $1=$ false to $5=$ true. Marsh's SDQ is one of the most wellvalidated measures of self-concept for children (Byrne, 1996). Cronbach's $\alpha$ was reported by Marsh as 0.85 (Marsh, 1990). In the present study, Cronbach's averaged 0.88 across the three time points.

\section{Classroom climate.}

The Classroom Climate measure is a subscale of the Diversity, Individual Development and Differentiation survey (DIDDs; Lupart, Whitley, Odishaw, \& McDonald, 2006) developed to assess student views in areas relevant to overall school functioning and inclusive education. The Classroom Climate subscale consists of seven items that evaluate students' perceptions of the support they receive from their teacher and their opportunities to take part in classroom activities. Children and youth respond to items on a five point scale ranging from $1=$ false to $5=$ true. In the present study, Cronbach's $\alpha$ averaged 0.72 across the three time points.

\section{Academic achievement.}

Academic achievement was assessed through student grades, which were obtained from report cards. Numerical grades were provided for students in grades 7 and 8 and letter grades for students in grades 4, 5 and 6. Letter grades were transformed into numerical grades to allow for quantitative analyses by choosing the midpoint of each grade range. For example, a grade of Brepresented a mark range of 70 to 72 (Ontario Ministry of Education, 1998), so a 71 was assigned for each B-. The academic average used in the present analyses was obtained by calculating the mean of the three strands of English Language Arts (reading, writing, oral/visual communication), five strands of Mathematics (number sense/numeration, measurement, geometry/spatial sense, patterning/algebra, data management/probability) and Science and Technology. These subjects were chosen as they appeared in all reporting periods, for students in every elementary grade (1 through 8$)$.

\section{Analyses}

Analyses were conducted to assess differences in self-concept, classroom climate and academic achievement for students with and without emotional/behavioural difficulties. Accordingly, a dichotomous variable was created. Students who scored in the top third of the Total Difficulties Score on the Strengths and Difficulties Questionnaire were identified as having emotional/behavioural difficulties (E/BD group, $n=23$, see Table 1) and those scoring in the bottom two thirds were identified as having low or no emotional/behavioural problems (Comparison group, $n=45$ ). It is important to note that the decision to select students in the top 
third of the group was not based on clinical cut-off scores or comparisons to external norms but rather was a way to select a group of students experiencing significant emotional and behavioural difficulties relative to their peers. Using the E/BD group status as a between-group factor, a repeated measures ANOVA was conducted with general and peer self-concept, classroom climate and academic achievement at each of the three time periods as dependent variables. Descriptive analyses indicated that none of the variables displayed a distribution with a degree of kurtosis or skewness greater than 2 standard errors. For academic achievement, the GreenhouseGeisser correction (Greenhouse \& Geisser, 1959) was applied due to violation of sphericity.

\section{Results}

Results of the repeated measures ANOVA reveal a significant multivariate effect for group, $F(4$, $59)=7.68, p<.01$ and time period, $F(8,55)=3.99, p<.01$ (see Figure 1 ). There was no significant interaction between the two. Univariate tests revealed significant differences between the $\mathrm{E} / \mathrm{BD}$ and Comparison groups on general self-concept, $F(1,62)=11.58, p<.01$, peer selfconcept, $F(1,62)=13.65, p<.01$, classroom climate, $F(1,62)=23.10, p<.01$, and academic achievement, $F(1,62)=9.80, p<.01$, at all time points. Scores were lower for students in the $\mathrm{E} / \mathrm{BD}$ group than the Comparison group in all instances.

Figure 1. Mean scores over time, by group.

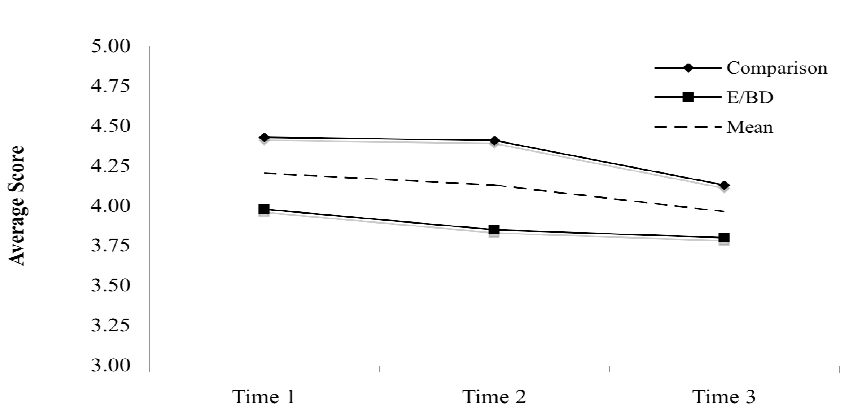

General Self-Concept
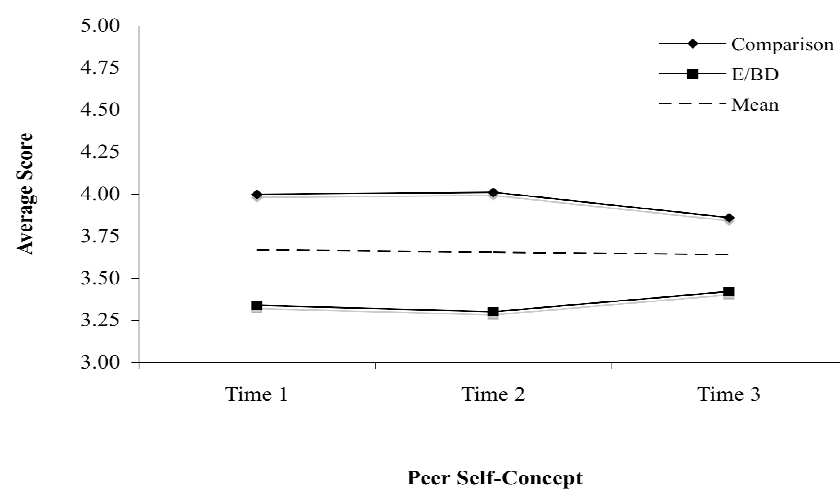
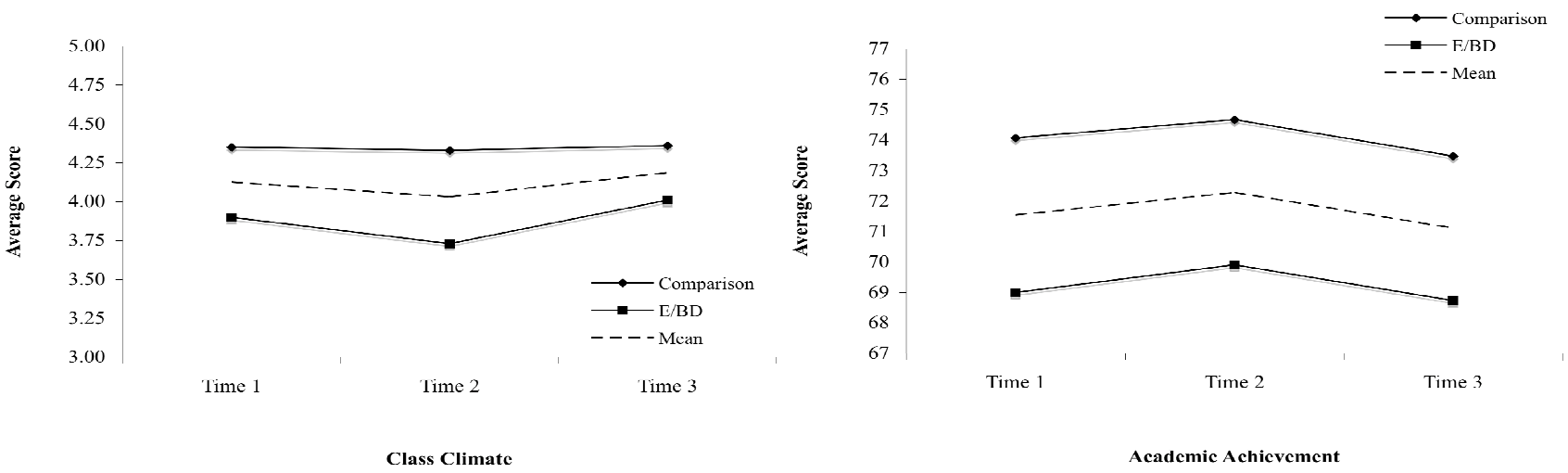

Brock Education, 19 (2) 
Across time, general self-concept, $F(2,124)=3.50, p<.03$ and classroom climate, $F(2$, $124)=3.16, p<.05$, changed significantly. A significant linear trend was noted for the former and a significant quadratic trend for the latter. Similar trends were observed with respect to general self-concept, which declined significantly across time for both groups, for peer selfconcept, which remained fairly stable for both groups, and for academic achievement, which displayed a significant quadratic trend but did not change significantly across time for either group. Classroom climate, however, showed dissimilar patterns for the E/BD and Comparison groups with the former reporting a significant quadratic trend and the latter remaining stable over time.

\section{Discussion}

The results show a number of interesting findings. Students with greater emotional/behavioural problems did report significantly lower levels of general and peer self-concept and they had significantly lower average school grades than those in the comparison group. They also perceived their class climate as being significantly more negative. Most importantly, these findings held across all three time periods indicating that the difficulties of the $\mathrm{E} / \mathrm{BD}$ group were not transient or solely the result of a poor classroom experience. Clearly then, regardless of the directionality of the relationship between emotional/behavioural difficulties and the outcome variables, the educational experiences of students in the E/BD group are more negative overall.

The present findings, particularly the negative, stable self-perceptions of a sample of students with E/BD, are supported by limited research (e.g. Whitley et al., 2009). Several studies have in fact found that students with E/BD rate themselves as similarly competent in terms of social and academic skills, in comparison to their typically-developing peers (e.g. Diener \& Milich, 1997; Hoza et al., 2002). Participants in these studies, however, have generally been children and youth (primarily boys) who have been referred to medical clinics by parents, teachers, and health professionals for having extreme levels of hyperactivity, impulsivity and/or inattention. The present sample consists of students who fall mainly within the average range of emotional and/or behavioural difficulties and represent a more typical group of elementary-aged students. The inability of students with E/BD to recognize their own areas of difficulty may be observed only among students with severe difficulties.

In terms of longitudinal effects, similar patterns were observed across groups for general self-concept, which declined significantly across time for both groups, for peer self-concept, which remained fairly stable for both groups, and for academic achievement, which displayed a significant quadratic trend but did not change significantly across time for either group. Classroom climate, however, showed dissimilar patterns for the E/BD and Comparison groups with the former reporting a significant quadratic trend and the latter remaining stable over time. Previous research supports a linear decline in general self-concept in late childhood and early adolescence, which typically shows a quadratic age effect as it increases somewhat in later secondary grades and into adulthood (Marsh, 1989; Marsh, Parker \& Barnes, 1985; Robins, Trzesniewski, Tracy, Gosling, \& Potter, 2002). Explanations for this pattern include the change that occurs as students move from an inflated sense of self during childhood, to a more realistic self-perception prompted by cognitive development allowing for greater self-awareness and awareness of the perceptions and evaluations of others (Harter, 1998; Marsh, 1989). Students may also face greater pressures, both academically and in terms of peer relations, as they enter 
middle school years and may internalize negative messages from others, thus resulting in lowered general self-concept (Eccles et al., 1989). As no differences in the changes were noted between groups, it appears that students with and without EBD experience this well-documented trend. One study by Montague and her colleagues (2008) did note a dramatically different pattern of self-concept scores for students with $\mathrm{E} / \mathrm{BD}$; as students without $\mathrm{E} / \mathrm{BD}$ reported higher scores through adolescence, those with E/BD reported declining self-concept after age 15 . Unfortunately, as the current study does not extend into secondary school, the generalizability of Montague's findings cannot be assessed. Future research will be needed to follow the selfconcept trajectory of students with $\mathrm{E} / \mathrm{BD}$ into late adolescence.

The stability of peer self-concept is in contrast to these studies that also document declines in this construct across childhood and into adolescence. Changes in peer self-concept are much less robust than those observed in all other domains, however, (e.g. Marsh, 1989) and may not be apparent in all student samples. Also, as students in the present sample remain in the same school for grade 7 and 8 and do not transition to middle or secondary school, the changes and potential difficulties in peer relationships that may result from exposure to new students and a new environment may not be relevant.

The remarkable similarity of the longitudinal trends in academic achievement for both groups of students is worth highlighting. While students with E/BD experience significantly lower achievement, their scores remain consistent over the year in which measures were obtained, as do those of their peers. This indicates that, regardless of environmental changes occurring from one grade to the next, students typically achieve at similar levels. For students without $\mathrm{E} / \mathrm{BD}$, this finding would be expected. That those with $\mathrm{E} / \mathrm{BD}$ continue to achieve at such similar and far lower levels than their peers is problematic. In the present study, information is not available as to the instructional methods or programs that were put in place to help these struggling students. However the pervasive, chronic nature of the difficulties experienced by this group of students that is documented in this study makes clear the need for timely, focused intervention.

The pattern observed for classroom climate over time is in contrast to that of self-concept or academic achievement. Students without E/BD continued to view their classroom climate similarly, and more positively than students with E/BD. Those in the E/BD group, however, show a slight decline from February to June and then a significant increase the following year. It is possible that the relationships between students with E/BD and their teachers worsen over the course of the year as their negative behaviours and relatively poor academic achievement persist. Students with E/BD, who experience multiple difficulties, may perceive their classroom environments and their teacher more positively at the beginning of the school year and then more negatively as the year goes on. In turn, their teachers may grow increasingly frustrated with the lack of improvement observed in students' behaviours and achievement. As neither earlier or later time points are available in the present study, and relevant research does not exist, this hypothesis cannot be confirmed.

One interesting and unique element of the present study is that students themselves identify the emotional and/or behavioural difficulties, rather than teachers or parents. The perceptions of adults in the lives of children and youth have generally been viewed as 'objective' or closer to reality than those of the students themselves. While we have no way of knowing how closely the identification of E/BD would have been between students and teachers in the present sample, we do know that the academic achievement of self-identified students was significantly lower than the comparison group. This indicates that teachers are aware of the difficulties of this 
group of students, at least in their schoolwork. Certainly there may be moderating variables not assessed in the present study, such as depression, which may contribute to an overall negative view of self on the part of the E/BD group resulting in low scores across self-report measures. However, given the significant relationships between student self-concept, engagement, teacher relationships and long-term outcomes (e.g. Mihalas et al., 2009; Zimmerman et al., 1997) the perspectives of students regarding their own behaviour, estimations of competence and class climate cannot be discounted.

The latter of these is particularly interesting. There is very limited existing research that has explored the perceptions of students with $\mathrm{E} / \mathrm{BD}$ of their classrooms and teachers. Whitley et al. (2009) found that a group of Canadian students with E/BD felt they were treated fairly by their teachers but did not like school as much as their typically-developing peers. The studentteacher relationship, which is an integral part of classroom climate, is of particular importance for students at-risk for academic failure, such as those with E/BD (e.g. Hamre \& Pianta, 2001; Sutherland et al., 2008). However, teachers may struggle to maintain positive relationships with students who are displaying potentially disruptive behaviour, lack social competence or who appear disengaged from their education. The promotion of functional behaviour assessments, positive behaviour supports, and whole-school approaches to supporting students with E/BD and their teachers (e.g. Christensen, Young \& Marchant, 2004; Hawken \& O’Neill, 2006; Mihalas et al., 2009; Sutherland et al., 2008), may help to ameliorate these relationships and enable more positive outcomes for students with $\mathrm{E} / \mathrm{BD}$.

The myriad challenges faced by students with E/BD make school-based interventions difficult. Although not included in most definitions of $\mathrm{E} / \mathrm{BD}$, the vast majority of students with this label experience significantly lower academic achievement than their typically-developing peers (e.g. Reid, Gonzales, Nordness, Trout, \& Epstein, 2004). The relationship between academic achievement and emotional and/behavioural problems is likely reciprocal; if students continue to struggle with their school work, they will continue to experience internalizing and externalizing behaviours and thus spend less time on task and have less positive relationships with their teachers, resulting in further academic declines (Sutherland et al., 2008). Although most students with E/BD who attend school in the United States are educated in segregated settings, many more in Canada are included in mainstream education settings. Students with moderate E/BD may face repeated suspension and/or expulsions as responses to behavioural outbursts or failing to attend school (e.g. Conroy, Hendrickson, \& Hester, 2004). This type of reactionary approach has been found to be largely ineffective in terms of improving future actions and may in fact contribute to worsening behaviours (Skiba \& Peterson, 1999; 2000). An altered school-wide focus that seeks to find ways to better include, rather than exclude students with $\mathrm{E} / \mathrm{BD}$ is necessary. This can be accomplished through the use of school-wide prevention programs that encourage social-emotional learning, a dual focus on the academic and behavioural needs of students with $\mathrm{E} / \mathrm{BD}$, and additional and specific training and support to allow teachers to better support students with E/BD (Alberta Learning, 2008; Hymel \& Henderson, 2006; Zins, Bloodworth, Weissberg, \& Walberg, 2004).

Many students with more severe E/BD present with complex needs that overwhelm classroom teachers faced with diverse classrooms and varied support. Results from the present study confirm the range of difficulties that students themselves are aware of. In light of this, there is growing recognition of the need for interdisciplinary, collaborative approaches to educating students with $\mathrm{E} / \mathrm{BD}$, including teachers, parents, behaviour specialists, board personnel and possibly mental health specialists. For example, Manitoba has created an intersectoral 
initiative to support students with severe E/BD that is known as a Circle of Care (Manitoba Education, Citizenship and Youth, 2009). The circle includes the student's school, family, and an outside agency such as Mental Health or Youth Corrections. Other provinces have created or are in the process of developing similarly comprehensive initiatives (e.g. Heath, Petrakos, Finn, Karagiannakis, McLean-Haywood \& Rousseau, 2004; Ontario Ministries of Education and Children and Youth Services, 2008).

Given the current results, it is also essential that the self-perceptions of students with $\mathrm{E} / \mathrm{BD}$ be considered as part of any intervention. While behaviour problems and poor achievement do present difficulties for educators and parents, they also contribute to poor selfworth and perceptions of competence as well as a negative view of the classroom environment on the part of the students themselves. Finding ways to build on students' strengths and promoting social acceptance of students with E/BD within schools may improve these selfperceptions and contribute to improved outcomes.

\section{Limitations \& Future Research}

There are a few limitations in the present study. First, participation at the two schools was fairly low and a number of students had incomplete data sets, resulting in a moderate sample size. As well, although the focus of the present study was on the perceptions of students selfidentified as having emotional/behavioural difficulties, it would have been beneficial to have had access to teacher and/or parent measures to confirm that these problems were evident across multiple settings. Future research may explore the views of multiple informants in regards to the academic and psychosocial experiences of students with E/BD. As well, while this study is one of few longitudinal explorations of the experiences of students with $\mathrm{E} / \mathrm{BD}$, it was still relatively short-lived at approximately one year. Following students for a longer period through their school careers may shed light on the processes involved in the successes and areas of need. Conclusion

As a group, students with E/BD experience poorer academic and psychosocial outcomes than their peers with and without exceptionalities. However, few Canadian studies have explored the experiences of these students early in their schooling, when intervention attempts are likely to be more successful. The present study documents the more negative and persistent perceptions that students hold as early as elementary school regarding their classroom climate and selfconcept. Findings also highlight the pervasive academic achievement that students with E/BD struggle with. It is essential that future research and practice consider the self-perceptions of students with E/BD as well as the contextual influences such as student-teacher and peer relationships in developing and evaluating interventions. 


\section{References}

Alberta Learning. (2009). Handbook for the identification and review of students with severe disabilities 2009/2010. Edmonton, AB: Author.

Alberta Learning. (2008). Supporting positive behaviour in Alberta schools: A school-wide approach. Edmonton, AB: Author. Retrieved July 10, 2009 from http://education.alberta.ca/admin/special/resources/behaviour.aspx

Baumeister, R. F., Campbell, J. D., Krueger, J. I., \& Vohs, K. D. (2005). Exploding the selfesteem myth. Scientific American, 292, 84-91.

Birch, S. H., \& Ladd, G. W. (1998). Chilren's interpersonal behaviors and the teacher-child relationship. Developmental Psychology, 34, 934-946.

Byrne, B. (1996). Measuring self-concept across the life span: Issues and instrumentation. Washington, DC: American Psychological Association.

Christensen, L., Young, K. R., \& Marchant, M. (2004). The effects of a peer-mediated positive behavior support program on socially appropriate classroom behavior. Education \& Treatment of Children, 27, 199-234.

Conroy, M. A., Hendrickson, J. M., \& Hester, P. P. (2004). Early identification and prevention of emotional and behavioral disorders. In R. B. Rutherford, M. M. Quinn, \& S. R. Mathur (Eds.), Handbook of Research in Emotional and Behavioral Disorders (pp. 199-215). New York: Guilford Press.

Deihl, L. M., Vicary, J. R., \& Deike, R. C. (1997). Longitudinal trajectories of self-esteem from early to middle adolescence and related psychosocial variables among rural adolescents. Journal of Research on Adolescence, 7, 393-411.

Diener, M. B. \& Milich, R. (1997). Effects of positive feedback on the social interactions of boys with attention deficit hyperactivity disorder: A test of the self-protective hypothesis. Journal of Clinical Child Psychology, 26, 256-265.

DuBois, D. L., Felner, R. D., Brand, S., \& George, G. R. (1999). Profiles of self-esteem in early adolescence: Identification and investigation of adaptive correlates. American Journal of Community Psychology, 27, 899-932.

Eccles, J. S., Wigfield, A., Flanagan, C. A., Miller, C., Reuman, D., \& Yee, D. (1989). Selfconcepts, domain values, and self-esteem: Relations and changes at early adolescence. Journal of Personality, 57, 283-310.

Goodman, R. (1999). The extended version of the Strengths and Difficulties Questionnaire as a guide to child psychiatric caseness and consequent burden. Journal of Child Psychology and Psychiatry, 40, 791-799. 
Goodman, R. (2001). Psychometric properties of the Strengths and Difficulties Questionnaire. Journal of the American Academy of Child and Adolescent Psychiatry, 40, 1337-1345.

Goodman, R., Meltzer, H., \& Bailey, V. (1998). The strengths and difficulties questionnaire: A pilot study on the validity of the self-report version. European Child \& Adolescent Psychiatry, 7, 125-130.

Greenhouse, S. W., \& Geisser, S. (1959). On methods in the analysis of profile data. Psychometrika, 24, 95-112.

Gresham, F. M. \& MacMillan, D. L. (1997). Social competence and affective characteristics of students with mild disabilities. Review of Educational Research, 67, 377-415.

Gunter, P. L., Coutinho, M. J., \& Cade, T. (2002). Classroom factors linked with academic gains among students with emotional and behavioral problems. Preventing School Failure, 46, 126-132.

Hamre, B. K. \& Pianta, R. C. (2001). Early teacher-child relationships and the trajectory of children's school outcomes through eighth grade. Child Development, 72, 625-638.

Harter, S. (1998). The development of self-representations. In W. Damon (Series Ed.) \& Nancy Eisenberg (Vol. Ed.), Handbook of child psychology, Vol. 3, Social, emotional, and personality development (5th edition), New York: Wiley.

Hawken, L. S. \& O’Neill, R. E. (2006). Including students with severe disabilities in all levels of school-wide positive behavior support. Research \& Practice for Persons with Severe Disabilities, 31, 46-53.

Heath, N. L., Petrakos, H., Finn, C., Karagiannakis, A., McLean-Heywood, D., \& Rousseau, C. (2004). Inclusion on the final frontier: A model for including children with emotional and behaviour disorders (E/BD) in Canada. International Journal of Inclusion, 8, 241-259.

Henderson, C. E., Dakof, G. A., Schwartz, S. J., \& Liddle, H. A. (2006). Family functioning, self-concept, and severity of adolescent externalizing problems. Journal of Child and Family Studies, 15, 719-729.

Hoza, B., Dobbs, J., Owens, J. S., Pelham, W. E., \& Pillow, D. R. (2002). Do boys with attention-deficits/hyperactivity disorder have positive illusory self-concepts? Journal of Abnormal Psychology, 111, 268-278.

Hoza, B., Pelham, W. E., Milich, R., Pillow, D., \& McBride, K. (1993). The self-perceptions and attributions of attention deficit hyperactivity disordered and nonreferred boys. Journal of Abnormal Child Psychology, 21, 271-286. 
Hymel, S., \& Henderson, N. R. (2006). Helping students who are experiencing persistent and/or serious discipline problems to succeed in school: The state of the evidence. Paper presented at the Ontario Ministry of Education Research Symposium, Toronto, ON.

Lahey, B. B., Schwab-Stone, M., Goodman, S., Waldman, I. D., Canino, G., Rahouz, P. J., et al. (2000). Age and gender differences in oppositional behavior and conduct problems: A cross-sectional household study of middle childhood and adolescence. Journal of Abnormal Psychology, 109, 488-503.

Lan, W. \& Lanthier, R. (2003). Changes in students' academic performance and perceptions of school and self before dropping out of schools. Journal of Education for Students Placed at Risk, 8, 309-332.

Lane, K. L., Carter, E. W., Pierson, M. R., \& Glaeser, B. C. (2006). Academic, social, and behavioural characteristics of high school students with emotional disturbances or learning disabilities. Journal of Emotional and Behavioral Disorders, 14, 108-117.

Landrum, T. J., Tankersley, M., \& Kauffman, J. M. (2003). What is special about special education for students with emotional or behavioral disorders? The Journal of Special Education, 37, 148-156.

Lubbers, M. J., Van Der Werf, M. P. C., Snijders, T. A. B., Creemers, B. P. M., \& Kuyper, H. (2006). The impact of peer relations on academic progress in junior high. Journal of School Psychology, 44, 491-512.

Lund, R. (1986). The self-esteem of children with emotional and behavioural difficulties. Maladjustment and Therapeutic Education, 5(1), 26-33.

Lupart, J. L., Whitley, J., Odishaw, J., \& McDonald, L. M. (2006). Whole school evaluation and inclusion: How elementary school participants perceive their learning community. In C. Dionne \& N. Rousseau (Eds.), Transformation des pratiques éducatives: la recherché sur l'inclusion (pp. 113-143). Québec, QC: Presses de L'Université du Québec.

Manitoba Education, Citizenship and Youth. (2009). Student services intersectoral initiatives: Multi-system submission for students with profound emotional/behavioural disorders. Retrieved July 10, 2009 from http://www.edu.gov.mb.ca/k12/specedu/intersectoral/ebdl3/index.html

Margerison, A. (1996). Self-esteem: Its effect on the development and learning of children with EBD. Support for Learning, 11(4), 176-180.

Marsh, H. W. (1988). Self Description Questionnaire: A theoretical and empirical basis for the measurement of multiple dimensions of preadolescent self-concept. A test manual and a research monograph. San Antonio, TX: Psychological Corporation. 
Marsh, H. W. (1989). Age and sex effects in multiple dimensions of self-concept: Preadolescence to early adulthood. Journal of Educational Psychology, 81, 417-430.

Marsh, H. W. (1990). A multidimensional, hierarchical model of self-concept: Theoretical and empirical justification. Educational Psychology Review, 2, 77-172.

Marsh, H. W., \& Ayotte, V. (2003). Do multiple dimensions of self-concept become more differentiated with age? The differential distinctiveness hypothesis. Journal of Education Psychology, 95, 687-706.

Marsh, H. W., Craven, R., \& Debus, R. (1998). Structure, stability, and development of young children's self-concepts: A multicohort-multioccasion study. Child Development, 69, 1030-1053.

Marsh, H. W. \& MacDonald Holmes, I. W. (1990). Multidimensional self-concepts: Construct validation of responses by children. American Educational Research Journal, 27, 89-117.

Marsh, H. W. \& O’Neill, R. (1984). Self Description Questionnaire III: The construct validity of multidimensional self-concept ratings by late adolescents. Journal of Educational Measurement, 21, 153-174.

Marsh, H. W., Parker, J., \& Barnes, J. (1985). Multidimensional adolescent self-concepts: Their relationship to age, sex, and academic measures. American Educational Research Journal, 22, 422-444.

Marsh, H. W., \& Shavelson, R. (1985). Self-concept: It's multifaceted, hierarchical structure. Educational Psychologist, 20, 107-123.

Mathai, J., Anderson, P., \& Bourne, A. (2002). The Strengths and Difficulties Questionnaire (SDQ) as a screening measure prior to admission to a Child and Adolescent Mental Health Service (CAMHS). Australian e-Journal for the Advancement of Mental Health, $1(3), 1-12$.

Mathai, J., Anderson, P., \& Bourne, A. (2004). Comparing psychiatric diagnoses generated by the Strengths and Difficulties Questionnaire with diagnoses made by clinicians. Australian and New Zealand Journal of Psychiatry, 38, 639-643.

Mihalas, S., Morse, W. C., Allsopp, D. H., \& McHatton, P. A. (2009). Cultivating caring relationships between teachers and secondary students with emotional and behavioral disorders. Remedial and Special Education, 30, 108-125.

Montague, M., Enders, C., Dietz, S., Dixon, J., \& Cavendish, W. M. (2008). A longitudinal study of depressive symptomatology and self-concept in adolescents. The Journal of Special Education, 42, 67-78. 
Nelson, J. R., Benner, G. J., Lane, K., \& Smith, B. W. (2004). Academic achievement of K-12 students with emotional and behavioral disorders. Exceptional Children, 71, 59-73.

Noble, E. \& Bowd, A. (2005). Definition and identification of children's attention and behaviour difficulties, with a focus on northern Ontario. Thunder Bay, ON: Centre of Excellence for Children and Adolescents with Special Needs.

Ontario Ministry of Education. (2001). Special education: A guide for educators. Toronto, ON: Author.

Ontario Ministry of Education. (1998). Guide to the provincial report card, Grades 1-8. Toronto, ON: Author.

Ontario Ministries of Education and Children and Youth Services. (2008). Student Support Leadership Initiative. Retrieved July 10, 2009 from cal2.edu.gov.on.ca/feb2008/studentSupport.pdf

Owens, J. S., \& Hoza, B. (2003). The role of inattention and hyperactivity/impulsivity in the positive illusory bias. Journal of Consulting and Clinical Psychology, 71, 680-691.

Reid, R., Gonzales, J. E., Nordness, P. D., Trout, A., \& Epstein, M. H. (2004). A meta-analysis of the academic status of students with emotional/behavioral disturbance. The Journal of Special Educaton, 38, 130-143.

Robins, R. W., Trzesniewski, K. H., Tracy, J. L., Gosling, S. D., \& Potter, J. (2002). Global selfesteem across the life span. Psychology and Aging, 17, 423-434.

Rosenberg, M. (1979). Conceiving the self. Malabar, FL: Robert E. Krieger.

Rosenberg, M., Schooler, C., Schoenbach, C., \& Rosenberg, F. (1995). Global self-esteem and specific self-esteem: Different concepts, different outcomes. American Sociological Review, 60, 141-156.

Sabornie, E. J., Cullinan, D., Osborne, S. S., \& Brock, L. B. (2005). Intellectual, academic, and behavioral functioning of students with high-incidence disabilities: A cross-categorical meta-analysis. Exceptional Children, 72, 47-63.

Skiba, R., \& Peterson, R. (1999). The dark side of zero tolerance: Can punishment lead to safe schools? Phi Delta Kappan, 80, 381-382.

Skiba, R. J., \& Peterson, R.L. (2000). School discipline at a crossroads: From zero tolerance to early response. Exceptional Children, 66, 335-346.

Slomkowski, C., Klein, R. G., \& Mannuzza, S. (1995). Is self-esteem an important outcome in hyperactive children. Journal of Abnormal Child Psychology, 23, 303-315. 
Soles, T., Bloom, E. L., Heath, N. L., \& Karagiannakis, A. (2008). An exploration of teachers' current perceptions of children with emotional and behavioural difficulties. Emotional and Behavioural Difficulties, 13, 275-290.

Sutherland, K. S., Lewis-Palmer, T., Stichter, J., \& Morgan, P. L. (2008). Examining the influence of teacher behavior and classroom context on the behavioral and academic outcomes for the students with emotional or behavioral disorders. The Journal of Special Education, 41, 223-233.

Treuting, J. J., \& Hinshaw, S. P. (2001). Depression and self-esteem in boys with AttentionDeficit/Hyperactivity Disorder: Associations with comorbid aggression and explanatory attributional mechanisms. Journal of Abnormal Child Psychology, 29, 23-39.

Visser, J., Daniels, H., \& Cole, T. (2001). Emotional and behavioural difficulties in mainstream schools. New York, NY: JAI Press.

Wagner, M., Kutash, K., Duchnowski, A. J., Epstein, M. H., \& Sumi, W. C. (2005). The children and youth we serve: A national picture of the characteristics of students with emotional disturbances receiving special education. Journal of Emotional and Behavioral Disorders, 13, 79-96.

Whiteside-Mansell, L., \& Corwyn, R. F. (2003). Mean and covariance structures analyses: An examination of the Rosenberg Self-Esteem Scale among adolescents and adults.

Educational and Psychological Measurement, 63, 163-173.

Whitley, J. L, Heath, N. L., \& Finn, C. A. (2008). The role of attention-deficit hyperactivity disorder in the self-perceptions of children with emotional and behavioural difficulties. McGill Journal of Education, 43, 65-80.

Whitley, J., Lupart, J. L., \& Beran, T. (2009). The characteristics and experiences of Canadian students receiving special education services for emotional/behavioural difficulties. Exceptionality Education International, 19(1), 14-31.

Winzer, M. (2008). Children with exceptionalities in Canadian classrooms, $8^{\text {th }}$ Edition. Toronto, ON: Pearson Education.

Wood, S. J. \& Cronin, M. E. (1999). Students with emotional/behavioral disorders and transition planning: What the follow-up studies tell us. Psychology in the Schools, 36, 327-345.

Zimmerman, M. A., Copeland, L. A., Shope, J. T., \& Dielman, T. E. (1997). A longitudinal study of self-esteem: Implications for adolescent development. Journal of Youth and Adolescence, 26, 117-141. 
Zins, J. E., Bloodworth, M. R., Weissberg, R. P., \& Walberg, H. J. (2004). The scientific base linking social and emotional learning to school success. In J. E. Zins, R. P. Weissberg, Zionts, P., Zionts, L., \& Simpson, R. L. (2002). Emotional and behavioral problems. 